\title{
INTERNALISASI NILAI-NILAI RELIEF CANDI PENATARAN DALAM PEMBELAJARAN SEJARAH UNTUK MENUMBUHKAN KESADARAN BUDAYA
}

\author{
Achmad Pandu Septiawan' ${ }^{1}$ Leo Agung1, S, Djono ${ }^{1}$
}

Diterima 20 Juli 2018, Dipublikasikan 31 Oktober 2018

CPenulis (2018)

\begin{abstract}
Culture is the national identity to build the glory of civilization in a country. Through the culture of the young generation, it is expected to be able to respect the dignity of the nation and to know the history of this country. But in reality the cultural awareness of the young generation has begun to erode the flow of globalization, this makes the culture in the country begin to decline its attractiveness. The phenomenon of cultural awareness that is starting to decline now is due to the lack of planting of character education in the Indonesian education system. Character education in history learning is needed to strengthen national identity through culture to deal with the negative effects of globalization. This study aims to: 1) Enter the values that exist in upgrading temple reliefs in history learning. 2) Cultivate cultural awareness through the values of the Penataran temple relief. This study uses descriptive qualitative research. Data collection techniques are carried out through observation, interviews, literature studies and documentation. The reliefs found in the Penataran temple include stories about Sri Tanjung, Sang Setyawan, Bubuksah Gagangaking, Ramayana, Kresnayana and animals or fables. The relief is full of religious values, honesty, tolerance, hard work and responsibilities that can be included in history learning to increase the knowledge of the younger generation about the cultural heritage of the ancestors in the past. Efforts to foster cultural awareness of the younger generation are: 1) Knowledge of the existence of various ethnic cultures, each of which has its identity and superiority, 2) An open attitude to respect and try to understand the culture of tribes outside the tribe of its own people, 3) Knowledge of the history of cultural development at various stages of the past, 4) Understanding in addition to caring for and developing elements of cultural heritage, we as a united Indonesian nation are also developing a new culture, namely national culture.
\end{abstract}

\section{Keywords}

Learning Models, Penataran Temple, Cultural Awareness

\section{PENDAHULUAN}

Globalisasi adalah tantangan besar bagi setiap negara, tidak terkecuali bangsa Indonesia. Pengaruh globalisasi juga membawa dampak bagi dengan masuknya kebudayaan baru di Indonesia. Dalam dampak negatifnya, arus globalisasi yang tengah masuk negara Indonesia membuat kebudayaan bangsa mulai berkurang peminatnya. Indonesia adalah negara yang memiliki keanekaragaman budaya, dengan keanekaragamannya seharusnya membuat generasi muda bangga, bukan malah sebaliknya dengan mengikuti arus budaya asing yang masuk ke negara ini.

1 FKIP Universitas Sebelas Maret Surakarta achmadpandu99@gmail.com 
Selain pengaruh negatif budaya asing yang masuk, perbedaan kebudayaan daerah juga selalu dijadikan alasan penyebab konflik dan sikap apatis terhadap budaya yang sudah dimiliki sejak dulu. Di mana kebudayaan daerah yang sering diagung-agungkan oleh masyarakat, sekarang mulai ditinggalkan dan menimbulkan perpecahan atas dasar perbedaan budaya setiap daerah. Jangan sampai arus globalisasi terus menggerus kebudayaan bangsa Indonesia yang mengatasnamakan modernisasi dan westernisasi, sehingga menghilangkan ciri khas budaya nasional. Konflik atas nama perbedaan dan modernisasi budaya sebenarnya terjadi karena kurangnya kesadaran budaya dari setiap individu atau kelompok. Thompkins et al, (2006) mengemukakan bahwa kesadaran budaya adalah proses untuk menjadi sadar terhadap nilai budaya yang dimiliki, pengaruhnya dan keterbatasan yang ditimbulkan oleh budaya yang dimilikinya. Kemudian kesadaran budaya adalah kemampuan seseorang untuk melihat dan menyadari akan nilai-nilai budaya yang ada di dalam dirinya dan di lingkungan sekitarnya. Oleh karena itu, perlu untuk memahami budaya yang berbeda dari dirinya, menyadari kepercayaannya, adat istiadat dan mampu menghormatinya.

Fenomena kesadaran budaya yang mulai berkurang ini disebabkan oleh kurangnya penanaman pendidikan karakter di dalam sistem pendidikan Indonesia. Upaya untuk mengembalikan kesadaran budaya melalui dunia pendidikan terus digalakkan. Penerapan kurikulum berbasis karakter kebangsaan menjadi target utama mengembalikan harkat dan martabat budaya Indonesia sebagai penguasa di negeri sendiri dan jati diri bangsa. Karakteristik pembelajaran sejarah di Sekolah Menengah Atas (SMA) dilihat dari tujuan dan penggunaannya dapat dibedakan dalam sejarah empiris dan normatif. Sejarah empiris menyajikan substansi kesejarahan yang bersifat akademis dan ilmiah. Menurut Suryo (1991) sejarah normatif menyajikan substansi kesejarahan yang ditentukan menurut nilai dan makna yang sesuai dengan tujuan pendidikan nasional. Misi dari pembelajaran sejarah adalah; (1) pendidikan intelektual dan (2) pendidikan nilai, pendidikan kemanusiaan, pendidikan moralitas, jati diri, nasionalisme serta identitas bangsa.

Tidak hanya pembelajaran yang efektif yang perlu dicapai, namun pembelajaran yang mengajarkan nilai-nilai juga perlu untuk diajarkan kepada peserta didik guna untuk menambah wawasan dan pengetahuan. Nilai-nilai tersebut berupa nilai pendidikan karakter yang patut untuk diajarkan, salah satunya adalah nilai-nilai yang terkandung pada relief-relief candi Penataran. Candi Penataran adalah sebuah warisan budaya leluhur yang berwujud tempat peribadatan umat Hindu dan Budha yang dibangun oleh raja Kertajaya dari Kediri pada tahun 1197 M serta tetap digunakan oleh raja-raja pada masa Singosari dan Majapahit (Suwardono, 2013:140). Diharapkan melalui nilai-nilai relief pada candi Penataran bisa menumbuhkan kesadaran budaya khususnya bagi generasi muda bangsa Indonesia

\section{METODE}

Pendekatan penelitian yang digunakan dalam penelitian ini adalah pendekatan kualitatif. Pendekatan ini dipilih karena penelitian ini berkaitan dengan perilaku masyarakat. Penelitian jenis kualitatif tidak hanya menetapkan penelitian berdasarkan variabel penelitian, tetapi keseluruhan situasi sosial yang meliputi aspek tempat, pelaku dan aktivitas yang berinteraksi secara sinergi (Sugiyono dalam Sari, 2013:229). Metode yang digunakan adalah metode deskriptif fenomenologi, dengan berusaha menelusuri, memahami dan menjelaskan fokus penelitian. Fokus penelitian ini adalah untuk menginternalisasikan nilai-nilai relief candi 
Penataran dalam pembelajaran sejarah untuk menumbuhkan kesadaran budaya bagi generasi muda.

Data primer dari penelitian ini adalah relief candi Penataran, dan data sekundernya adalah nilai-nilai yang terkandung dalam relief tersebut. Teknik pengumpulan data dilakukan melalui observasi pengamatan pada relief candi Penataran, wawancara, studi pustaka dan dokumentasi. Sedangkan untuk teknik analisis data digunakan model interaktif yang meliputi reduksi data, sajian data dan verifikasi.

\section{HASIL DAN PEMBAHASAN}

Menurut Munandar (2011:175) relief adalah seni pahat atau ukiran tiga dimensi yang biasanya dibuat di atas batu. Bentuk ukiran ini biasanya dijumpai pada bangunan candi atau tempat-tempat bersejarah. Setiap relief yang khususnya terpahat di dinding-dinding candi pada masa Hindu-Budha selalu memiliki makna simbolis dan mengandung nilai-nilai dalam setiap panelnya. Pesan-pesan pada relief mengandung kisah-kisah yang sarat akan nilai budaya leluhur, simbol-simbol yang dipakai pada relief cerita mempunyai hubungan yang erat dengan unsur-unsur yang ada dalam masyarakat (Kieven, 2014:235). Dalam setiap panel di relief candi Penataran terdapat kisah-kisah menarik dan mengandung nilai-nilai karakter yang bisa dimasukkan dalam pembelajaran sejarah, perhatikan tabel 1 .

Tabel 1. Nilai Karakter Relief Candi Penataran

\begin{tabular}{lll}
\hline \multicolumn{1}{c}{ No } & \multicolumn{1}{c}{ Relief } & \multicolumn{1}{c}{ Nilai } \\
\hline 1 & Sri Tanjung & Jujur, cinta tanah air, tanggung jawab \\
2 & Sang Setyawan & Religius, kerja keras, mandiri \\
3 & Bubuksah Gagangaking & Religus, toleransi \\
4 & Ramayana & Kerja keras, cinta tanah air, tanggung jawab, mandiri \\
5 & Kresnayana & Tanggung jawab, jujur, bekerja keras \\
6 & Fabel: & Jujur, kerja keras, tanggung jawab, kreatif \\
& $\begin{array}{l}\text { a. Angsa dan Kura-Kura } \\
\text { b. Harimau, dan Kera } \\
\text { c. Lembu dan Buaya } \\
\text { d. Pemburu yang tertipu }\end{array}$ & \\
& & \\
\hline
\end{tabular}

Internalisasi adalah upaya yang harus dilakukan secara berangsur-angsur, berjenjang dan istiqomah. Penanaman, pengarahan, pengajaran dan bimbingan dilakukan secara terencana, sistematis dan terstruktur dengan menggunakan pola dan sistem tertentu (Nasir, 2010:59). Proses internalisasi yang dikaitkan dengan pembinaan peserta didik ada tiga tahap yang mewakili proses terjadinya internalisasi (Muhaimin, 1996:153), yaitu:

a. Tahap transformasi nilai.

Tahap ini merupakan suatu proses yang dilakukan oleh pendidik dalam menginformasikan nilai-nilai yang baik dan kurang baik. Contoh: Guru mengajarkan tentang isi dari relief di candi Penataran kepada peserta didik

b. Tahap transaksi nilai

Tahap pendidikan nilai dengan jalan melakukan komunikasi dua arah atau komunikasi antar peserta didik dengan pendidik yang bersifat interaksi timbal balik. Contoh: Guru berusaha memberi contoh dan menekankan pentingnya nilai-nilai yang terkandung dalam candi Penataran kepada peserta didik

c. Tahap trans internalisasi.

Pada tahapan ini tidak semata mata hanya mengajarkan melalui komunikasi verbal melainkan juga contoh mental dan kepribadian yang akan ditonjolkan.. Contoh: Guru 
mengimplementasikan nilai-nilai relief candi Penataran kepada peserta didik dengan tujuan untuk menumbuhkan kesadaran budaya.

Nilai-nilai pendidikan karakter yang terdapat di dalam relief candi Penataran yang disampaikan dalam pembelajaran sejarah diharapkan mampu menumbuhkan kesadaran budaya dengan pengantar materi sejarah Hindu-Budha di Nusantara. Proses dalam menginternalisasikan nilai-nilai relief candi Penataran dalam pembelajaran sejarah untuk menumbuhkan kesadaran budaya bagi generasi muda melalui pembelajaran sejarah dapat dilihat dari kerangka berpikir pada diagaram1.

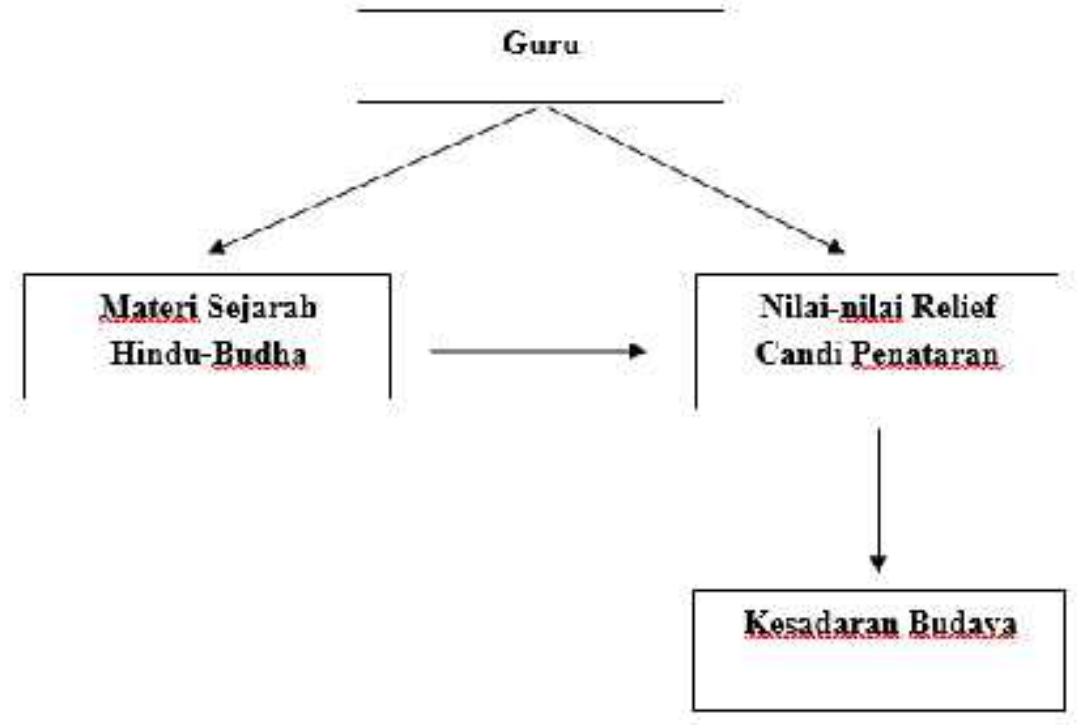

Diagram 1. Kerangka Berpikir

Upaya untuk menginternalisasikan nilai-nilai relief candi Penataran dapat juga diimplementasikan dalam pembelajaran sejarah melalui beberapa cara sebagai berikut.

a. Mengembangkan cerita pada setiap relief di candi Penataran menjadi media pembelajaran berbasis komik sejarah.

b. Mengembangkan pembelajaran sejarah berbasis study tour atau field trip ke candi Penataran.

c. Mengembangkan nilai-nilai relief candi Penataran ke dalam model pembelajaran sejarah yang disesuaikan dengan materi terkait sejarah masuk dan berkembangnya Hindu-Budha di Indonesia.

d. Mengembangkan strategi pembelajaran yang bervariatif dalam menanamkan nilai-nilai relief candi Penataran.

Menurut Warto (2017) tujuan kurikulum pendidikan sejarah selalu diasosiasikan dengan tiga pandangan. Pertama, "perenialisme" yang memandang bahwa pendidikan sejarah sebagai wahana "transmission of culture". Pengajaran sejarah hendaklah diajarkan sebagai pengetahuan yang dapat membawa siswa kepada penghargaan yang tinggi terhadap "the glorius past". Sementara itu, dalam Peraturan Menteri Pendidikan No. 22/ 2006 dijelaskan mengenai tujuan pembelajaran sejarah yaitu untuk membentuk watak dan peradaban bangsa yang bermartabat serta membentuk manusia Indonesia yang memiliki rasa kebangsaan dan cinta tanah air.

Tugas guru dan pemerintah dalam Pembelajaran sejarah adalah meningkatkan kesadaran budaya dan kesadaran sejarah kepada peserta didik dan masyarakat luas. Menurut Ismail (2006) 
sebagian besar pelajar memang menemukan manfaat positif dalam kehidupan lintas budaya dalam pengalaman belajar, namun sejumlah orang mengalami dampak psikologis tertentu dan efek penghambat lainnya dari budaya kedua.

Kesadaran budaya merupakan sikap di mana seseorang menghargai, memahami, dan mengerti akan adanya perbedaan-perbedaan yang ada dalam budaya tersebut. Untuk menumbuhkan jiwa yang sadar akan budaya tersebut, berikut sekiranya ada 4 cara, yaitu:

a. Penanaman sikap multikulturalisme sejak dini.

b. Sosialisasi budaya melalui lembaga pendidikan.

c. Penyelenggaraan berbagai pentas budaya.

d. Mencintai dan menjaga budaya yang dimiliki.

Menurut Sedyawati (2012:330) adanya kesadaran budaya ditandai dengan empat pengertian, yaitu; (1) pengetahuan akan adanya keberagaman kebudayaan suku bangsa, (2) sikap terbuka untuk menghargai, (3) pengetahuan akan adanya riwayat perkembangan budaya, dan (4) pengertian merawat warisan budaya. Kesadaran budaya ini menjadi suatu filter yang harus mulai ditanamkan dalam diri peserta didik sehingga menumbuhkan sikap sensitif dan kritis terhadap kebudayaan yang masuk, namun tetap responsif dan bertanggung jawab. Selanjutnya melalui nilai-nilai relief candi Penataran yang diinternalisasikan ke dalam pembelajaran sejarah dengan tujuan menumbuhkan kesadaran budaya dan mempersiapkan peserta didik dalam menghadapi tantangan masa depan melalui pembelajaran yang sesuai.

\section{SIMPULAN}

Pembelajaran sejarah dalam pelaksanaannya dapat diarahkan untuk mendidik siswa agar memiliki kesadaran budaya dan mengembangkan nilai-nilai yang dapat menunjang kesadaran budaya, di mana arus kebudayaan global bersama dampak negatifnya mulai mengancam kebudayaan nasional. Melalui internalisasi nilai-nilai relief candi Penataran dalam pembelajaran sejarah diharapkan dari generasi muda akan tumbuh kesadaran tentang budaya dan mampu untuk melestarikannya.

Pembelajaran sejarah mampu memberikan media, model dan strategi terhadap upaya menumbuhkan kesadaran budaya dengan menginternalisasikan nilai-nilai karakter bangsa sehingga siswa memiliki sikap yang cerdas dan bertanggung jawab dalam menghadapi masuknya arus kebudayaan global.

Guru dan sekolah perlu mengembangkan pembelajaran sejarah berbasis nilai-nilai relief yang mengandung pendidikan karakter untuk menumbuhkan kesadaran budaya generasi muda dalam pengaruh arus kebudayaan globalisasi yang masuk ke Indonesia. Pengembangan pembelajaran sejarah bisa melalui implementasi nilai-nilai relief ke dalam strategi pembelajaran, model, media dan observasi sejarah.

\section{DAFTAR PUSTAKA}

Ismail, Cakir. (2006). Developing Cultural Awareness In Foreign Language Teaching. Kirikkale University. Turkey

Kieven, Lydia. (2014). Menelusuri Figur Bertopi Dalam Relief Candi Zaman Majapahit:

Pandangan Baru terhadap Fungsi Religius Candi-Candi Periode Jawa Timur Abad ke-14 dan ke-15. KPG. Jakarta

Muhaimin. (1996). Strategi Belajar Mengajar Citra Media. Surabaya 
Munandar, Agus Aris. (2012). Proxemic Relief Candi-Candi Abad Ke-8-10. WWS. Jakarta.

Nasir, Ridlwan. (2010). Mencari Tipologi Format Pendidikan Ideal. Pustaka Agung. Yogyakarta.

Sari, Ika Dwi Retno. (2013). Visualisasi Nilai Pendidikan Karakter Dalam Relief Cerita Hewan Di Candi Sojiwan. Berkala Arkeologi. Vol. 33 Edisi No. 2/ November.

Setyawati, Edi. (2012). Budaya Indonesia: Kajian Arkeologi, Seni dan Sejarah. Raja Grafindo Persada. Jakarta

Suwardono. (2013). Sejarah Indonesia Masa Hindu Budha. Ombak. Yogyakarta

Thompkis, Donald., Galbraith Diane., Thompkins, Patricia. (2006). Universalisme, Particularism, and Cultural Self-Awareness: a comparsion of American and Turkhish university student. Journal of Internasional Business and Culture Studies. P 1-8

Warto. (2017). Disampaikan dalam acara Diskusi Sejarah dengan tema "Internalisasi NilaiNilai Sejarah sebagai Upaya Meningkatkan Rasa Nasionalisme dan Sadar Sejarah kepada Generasi Muda”, pada Rabu 20 September 2017 di FIS UNY Yogyakarta. 